\title{
General or Local Anaesthesia in One-Day Thyroid Surgery-Does It Matter?
}

\author{
Maya Belitova', Rumen Pandev², Dimitar Karadimov ${ }^{1}$ \\ 'Department of Anaesthesiology and Intensive Care, University Hospital "Queen Giovanna"-Sofia, Sofia, Bulgaria \\ 2Department of One-Day Surgery, University Hospital "Queen Giovanna"-Sofia, Sofia, Bulgaria
}

\begin{abstract}
Objective: We aimed to determine the safety and feasibility of general anaesthesia (GA) compared with local anaesthesia + Monitored Anaesthesia Care (LA+MAC) for One-Day Thyroid Surgery (ODTS); to assess patient and operator satisfaction with either of the anesthetic approaches.
\end{abstract}

Material and Methods: We reviewed prospectively 130 patients who underwent ODTS from 2008 to 2011.64 patients were operated on under GA and 62 - under LA+MAC. All variables of patient demographic characteristics, duration and type of operation, postoperative complications, difficulty in airway management and postoperative opiate consumption were recorded and analyzed.

Results: There is no difference in respect to length of stay, discharge time and major/minor complications rate between two groups, but in the LA+MAC group, pain appears earlier and is more severe $(56 \mathrm{~min}$; VAS 6, 5) than in GA patients (223 min; VAS 1, 5; $p<0.001)$. Patient satisfaction was similar but the operator preference was greater for GA.

Conclusion: In experienced hands LA with MAC for Thyroidectomy is a safe and wise choice, but GA is even more so!

Key Words: One-day thyroid surgery, general anaesthesia, local anaesthesia, MAC, complications

Received: 05.10.2011

Accepted: 21.11.2011

\section{Introduction}

Thyroid disease has long been recognized: goitres were first described by the Chinese in $2700 \mathrm{BC}$; thyroid surgery was first described in the $12^{\text {th }}$ Century and until early in the $20^{\text {th }}$ century, it was performed using local anaesthesia. After that time, with the development of newer and safer anesthetic techniques, and with the modern intravenous anaesthetic agents like propofol, midazolam, and fentanyl, thyroidectomy was performed exclusively under general anaesthesia and in inpatient settings. The current trend now favors minimally invasive thyroid surgery techniques, ambulatory approach, shortening of hospital stay and once more utilizes preferably Local anaesthesia + Monitored Anaesthesia Care (LA + MAC) (1-6). However, the complexity of the procedure may vary from excision of a single nodule to removal of the entire thyroid gland with lymph dissection to treat cancer, or extirpation of a retrosternal goitre to relieve tracheal compression. To do these more complex and extensive surgical procedures, GA is obligatory $(3,7,8)$. Many prospective trials discuss anesthetic approach feasibility and safety for one-day thyroid surgery (ODTS), but many unsolved questions still exist. Because comparative studies of Local vs. General Anaesthesia (GA), especially for OneDay thyroid surgery, are few, thyroidectomy anaesthesia is rich in popular myths which have no provenscientific base (9-12).
The study aimed, as a primary objective, to prospectively determine the safety and feasibility of GA compared with LA + MAC, especially for One-day thyroid surgery, and also to assess patient and operator satisfaction with either of the anesthetic approaches for thyroid surgery.

\section{Material and Methods}

One hundred thirty consecutive patients signed a written informed consent to participate in the randomization. They underwent thyroid surgery, performed by a single senior surgeon, from 2008 to 2011 in University Hospital One-Day settings. The patients were prospectively assigned in 2 groups: GA group $(n=64)$ and LA+MAC group $(n=62)$. All variables (gender, American Society of Anesthesiologists (ASA) status, duration and type of operation, postoperative complicationsmajor/minor, difficulty in airway management, postoperative pain and opiate consumption) were recorded and analyzed.

Study frame-Setting: Department of One-Day Surgery, University Hospital "Queen Giovanna"-Sofia. Selection criteria (given by the surgeon and anesthesiologist) for One-Day surgery are: elective primary thyroid surgery, benign or malignant pathologies of thyroid or parathyroid gland, patient's age $>18$ years, written informed consent to participate in the study, euthyroid state, patients seen in the preadmission assessment of the department by an anaesthesiologist 
and cleared for one-day surgery. Compensated concomitant pathologies: obesity, diabetes mellitus, cardiopathy, bronchopathy, nephropathy or hepatopathy with good functional capacity of the patients were not a contraindication for oneday surgery. The study coordinator from the biostatistics department independently assigned randomization once the patient fulfilled the selection criteria. Exclusion criteria: patient's refusal. Study protocol: detailed preanesthetic physical examination of patients consisting of neck, routine systemic and hematological examination, T3, T4, TSH, chest X-ray and ECG were carried out on the day before surgery. After the anesthetic review, patients were sent home and were called back with necessary instructions in the morning of the day of surgery at 7,30 a.m. Total thyroidectomies were scheduled as a first procedure of the day; also hemithyroidectomies and subtotal thyroidectomies were completed by 4.00 p.m. to allow adequate time for observation.

Anaesthesia protocol GA group: The anesthetic management was carried out by a single senior anesthesiologist. 64 patients were operated on under GA. Premedication with Midazolam (Dormicum ${ }^{\circledR}$ Roche) $0.05 \mathrm{mg} / \mathrm{kg}+$ Fentanyl (Fentanyl citrate, Gedeon Richter $\left.{ }^{\circledR}\right) 2$ mcg/kg i.v., was followed by induction with Propofol (Diprivan 1\%, Astra Zeneca ${ }^{\circledR}$ )-2 mg/ $\mathrm{kg}$ and depolarizing relaxation with Succinylcholine (Lysthenone $1 \%$, Nycomed Austria, Linz) $1 \mathrm{mg} / \mathrm{kg}$. After intubation of the trachea, low flow $(2.00 \mathrm{l} / \mathrm{min})$ inhalational anaesthesia was given with Isoflurane (Abbott ${ }^{\circledR}$, USA) (ET Iso-0.8 vol \% in a gas mixture of $\mathrm{O}_{2}: \mathrm{N}_{2} \mathrm{O}=1: 1$; $\mathrm{BIS}$ index was kept $<30$ during entire procedure). Before the skin incision, Fentanyl was given incrementally up to a total dose of $10 \mathrm{mcg} / \mathrm{kg}$. Nondepolarizing muscle relaxation and more opiate were not needed intraoperatively. With the beginning of the skin closure, Isoflurane was switched off and $100 \%$ of oxygen was given to the patients, followed by extubation of the trachea. Anaesthesia protocol LA+MAC group: Superficial cervical plexus block (SCPB) was achieved with $5 \mathrm{ml} 1 \%$ Lidocaine (Sopharma ${ }^{\circledR}$, Bulgaria)+Field block with $15 \mathrm{ml} 1 \%$ Lidocaine. Monitored anaesthesia care consisted of Midazolam $0.07 \mathrm{mg} / \mathrm{kg}$ given in increments+Fentanyl $2-3 \mathrm{mcg} / \mathrm{kg}$. Using this approach, we aimed at and achieved a Ramsay Sedation Score 3-4 from the original Ramsay Sedation Scale (13): 1. Patient is anxious and agitated or restless, or both; 2. Patient is cooperative, oriented and tranquil; 3 . Patient responds to commands only; 4. Patient exhibits brisk response to light glabellar tap or loud auditory stimulus; 5 . Patient exhibits a sluggish response to light glabellar tap or loud auditory stimulus; 6. Patient exhibits no response.

No patient from the study group received prophylactic antibiotics at any time. No drain was used. Meticulous attention was paid to haemostasis. For this reason, in the GA group, especially in patients with extensive thyroid surgery, intrapulmonary pressure $\geq 40 \mathrm{mmHg}$ was applied before surgical closure of the wound with a high pressure maneuver. 5 min after the skin incision, $8 \mathrm{mg}$ Dexamethasone+10 mg Methoclopramide i.v. for postoperative nausea and vomiting prophylaxis were also given. Prophylactic $10 \mathrm{ml}$ of $10 \%$ calcium gluconate intravenously was administered to prevent early postoperative hypocalcaemia in all patients in the GA group. Post surgical protocol: after completion of the surgical procedure, patients were admitted (overnight admission) in General Unit of OneDay Surgery Department (GUODS) where there was no specialized monitoring (no PACU). Postoperative analgesia was achieved with $3 \times 1,0$ i.v. Perfalgan (Bristol-Myers ${ }^{\circledR}$ Squibb) regularly. Also, patients received Oxycontin (OxyContin, Bard Pharmaceuticals Limited ${ }^{\circledR}$ UK) tab.10 mg p.o. only if pain intensity on Visual Analog Scale (VAS) was $\geq 4$. All patients except those who developed major postoperative complications were discharged at the $23^{\text {th }}$ postoperative hour regardless of the anaesthesia method. To prevent late postoperative hypocalcaemia, serum ionized calcium level was measured at the $20^{\text {th }}$ postoperative hour and on the $3^{\text {th }}$ postoperative day. All patients who underwent hemi or total thyroidectomy received prescriptions for oral calcium supplementation (4x500 mg).

\section{Statistical analysis}

We used the SPSS version 16, 0 and Microsoft Ultimate. Continuous variables were compared using a 2-sample t test or the Wilcoxon nonparametric procedure. Categorical variables, including sex, were compared using the $\chi^{2}$ test or the Fisher exact test. All the statistical comparisons were made using a $5 \%$ level of significance.

\section{Results}

One hundred thirty consecutive patients agreed to the randomization and were enrolled in the study. Of these, three patients were excluded. Their procedures started later and finished later (after 5:30 p.m.), due to technical circumstances in the operating room. Not enough data were available for one of the resting patients, so the following analysis encompasses the remaining 126 patients. $98 \%$ of them were healthy or had a compensated systemic disease: ASA I $(n=35)$, II $(n=34)$, III $(n=55)$ and only $2 \%$ had limited capacity, depending on daily medicine intake or specialized medical care - ASA IV $(n=2)$. Most of them (78\%) were women. Table 1 summarizes the baseline characteristics and statistical analysis of the randomized patients by study group. Both groups were similar in terms of patient demographics, primary diagnosis, and type of surgical procedures (in each group, about $50 \%$ of the patients received bilateral thyroidectomy). Other variables such as the duration of surgery, time spent in various stages of patient surgical care, early complications rate, occurrence of initial postoperative nausea and/or vomiting, severity of postoperative pain, total opiate consumption and patient satisfaction with their anaesthetic care are summarized on Table 2. Statistical analysis is given also. Intraoperative conversions from local anaesthesia with MAC to general anaesthesia were not needed. No patient, irrespective of ASA status or type of anesthetic approach, had prolonged and delayed recovery from anaesthesia or showed any adverse reactions. Patients who received local anaesthesia with MAC spent less time in the operating room than patients under GA, their surgical procedure was also shorter, but the difference was not statistically significant. Logically, these patients spent more time in GUODS.

Postoperative pain appeared earlier and was much stronger in the LA group (56 min after OP, versus $223 \mathrm{~min}$ ). VAS $\geq 5$ was noted in $24 \%$ of these patients. These are the only 
Table 1. Demographic and baseline characteristics of study groups

\begin{tabular}{|c|c|c|c|}
\hline Variable & $\begin{array}{c}\text { GA } \\
(n=64)\end{array}$ & $\begin{array}{c}\mathrm{LA}+\mathrm{MAC} \\
(\mathrm{n}=62)\end{array}$ & $\begin{array}{c}\mathrm{p} \\
\text { value }\end{array}$ \\
\hline Age, mean $\pm S D, y$ & $56.4 \pm 17.8$ & $52.9 \pm 13.9$ & 0.37 \\
\hline Female/Male, No & $49 / 15$ & $50 / 12$ & 0.56 \\
\hline Height, mean $\pm S D, m$ & $158.9 \pm 9.8$ & $160.2 \pm 10.1$ & 0.78 \\
\hline Weight, mean $\pm S D, k g$ & $81.6 \pm 18.5$ & $79 \pm 20.7$ & 0.71 \\
\hline ASA-1/2/3/4, n & $16 / 17 / 29 / 2$ & $19 / 17 / 26 / 0$ & 0.85 \\
\hline \multicolumn{4}{|l|}{ Primary Dg, n } \\
\hline Thyroid cancer & 12 & 7 & 0.48 \\
\hline Graves disease & 3 & 4 & 0.99 \\
\hline Multinodular goiter & 49 & 51 & 0.99 \\
\hline $\begin{array}{l}\text { Unilateral lobectomy, } \\
n, \%\end{array}$ & $21(32)$ & $26(41)$ & 0.79 \\
\hline $\begin{array}{l}\text { Bilateral thyroidectomy, } \\
n, \%\end{array}$ & $33(51)$ & $34(54)$ & 0.99 \\
\hline $\begin{array}{l}\text { Bilateral thyroidectomy } \\
\text { plus central lymph node } \\
\text { dissection, n, \% }\end{array}$ & $10(15)$ & $2(3)$ & 0.21 \\
\hline
\end{tabular}

patients who received Oxycontin for postoperative pain relief. In fact, $88 \%$ of the GA patients did not experience any pain after operation (some of them described it as "only minor discomfort in the thyroid gland area"). All patients with VAS $\leq 4$ ( $12 \%$ of the GA group vs. $61 \%$ of the LA+MAC group), were medicated regularly with Perfalgan 3 times daily 1, 0 i.v.

There was no significant difference between the groups with respect to nausea and vomiting or other early postoperative complications within the first 24 hours. Both groups had 1 patient with transient vocal cord paresis with subsequent complete recovery of the voice. Also, transient voice change was observed in 2 patients from both groups. Two of them, heavy smokers (smoking more than 50 cigarettes per day) from the GA group, complained of previous episodes of voice changes, but they did not note this in the preanesthetic interview. Both patients refused an indirect laryngoscopic follow-up examination despite our repeated attempts to persuade them to do so. Three patients from the GA group and one from the LA+MAC group complained of a headache which had started preoperatively in two of them, from the GA group. They traveled more than $500 \mathrm{~km}$ by car on the night before the operation on their own decision and had pain relief after taking a non-steroid anti-inflammatory drug. The other two patients complained of previous migraine attacks. They obtained pain relief after taking their regular antimigraine medication.

Despite our prophylaxis of early hypocalcaemia, asymptomatic hypocalcaemia documented at the $20^{\text {th }}$ hour postoperatively, occurred in 2 patients in each group. They had total thyroidectomies with reimplantation of parathyroid glands. They responded to oral calcium supplementation. On the $3^{\text {th }}$ day after OP, this complication was fully resolved.
Table 2. Study groups outcome

\begin{tabular}{|c|c|c|c|}
\hline Characteristics & $\begin{array}{c}\text { GA } \\
(n=64)\end{array}$ & $\begin{array}{c}\mathrm{LA}+\mathrm{MAC} \\
(\mathrm{n}=62)\end{array}$ & $\begin{array}{c}p \\
\text { value }\end{array}$ \\
\hline $\begin{array}{l}\text { Duration of surgery, min } \\
(m e a n \pm S D)\end{array}$ & $127 \pm 36$ & $98 \pm 23$ & 0.19 \\
\hline $\begin{array}{l}\text { Time in OR, mean } \pm S D \text {, } \\
\text { min }\end{array}$ & $152 \pm 31$ & $139 \pm 20$ & 0.10 \\
\hline Time in GUODS, $\mathrm{h}$ & $20.8 \pm 0.5$ & $21.3 \pm 0.5$ & 0.96 \\
\hline $\begin{array}{l}\text { Hospital readmission, } \\
n, \%\end{array}$ & $2(3)$ & $2(3)$ & 0.98 \\
\hline $\begin{array}{l}\text { Postoperative pain, No } \\
\text { (No pain/NAS } \leq 4 / \text { VAS } \geq 4 \text { ) }\end{array}$ & $56 / 8 / 0$ & $9 / 38 / 15$ & 0.001 \\
\hline $\begin{array}{l}\text { Onset of postoperative pain, } \\
\text { min after OP }\end{array}$ & $223 \pm 34$ & $56 \pm 18$ & 0.001 \\
\hline $\begin{array}{l}\text { Oxycontin, mg/patient } \\
\text { VAS } \geq 5 \text { (mean } \pm S D \text { ) }\end{array}$ & 0 & $13.7 \pm 2.5$ & 0.001 \\
\hline Nausea within $24 h, n, \%$ & $13(20)$ & $12(19)$ & 0.99 \\
\hline Vomiting within $24 h, n, \%$ & $2(3)$ & $2(3)$ & 0.99 \\
\hline $\begin{array}{l}\text { Transient voice change, } \\
n, \%\end{array}$ & $2(3)$ & $2(3)$ & 0.74 \\
\hline Headache, n, \% & $3(4)$ & $1(2)$ & 0.78 \\
\hline $\begin{array}{l}\text { Transient vocal cord paresis, } \\
n, \%\end{array}$ & $1(2)$ & $1(2)$ & 0.99 \\
\hline $\begin{array}{l}\text { Asymptomatic hypocalcaemia, } \\
n, \%\end{array}$ & $2(3)$ & $2(3)$ & 0.99 \\
\hline Haematoma, n, \% & $1(2)$ & $1(2)$ & 0.99 \\
\hline $\begin{array}{l}\text { Without any complication, } \\
n, \%\end{array}$ & $37(56)$ & $37(57)$ & 0.99 \\
\hline $\begin{array}{l}\text { Patient satisfaction with } \\
\text { anaesthesia, (yes/no) }\end{array}$ & $62 / 2$ & $60 / 2$ & 0.99 \\
\hline
\end{tabular}

The most serious complication that we observed was haematoma formation in 1 patient in each group. The patient from the GA group was a 57 year old woman, who underwent total thyroidectomy for medullary cancer with central lymph node dissection. In the GUODS she was found to have significant neck swelling with mild respiratory compromise 17 hours after surgery. The patient from the LA group was a 66 year old man, who underwent total thyroidectomy for papillary thyroid cancer. Seven hours postoperatively, he started to have some swallowing difficulty and a local postoperative pressure in the neck. They were returned to the OR immediately where decompression and haemostasis were performed under GA. No active source of bleeding was found. The blood loss was approximately $150 \mathrm{~mL}$ in the former case, and about $100 \mathrm{ml}$ in the letter. The rest of the postoperative period was uneventful for the two patients.

Approximately 37 patients (56\%) who received local anaesthesia with MAC and 37 patients (58\%) who received general anaesthesia had no identifiable complications $(p=.99)$. Patients in both groups were similarly satisfied with their anaesthesia experience $(p=.99)$. In fact, preoperative fear and 
anxiety in all the patients were very high. Those from the LA group agreed to participate in the study, after our reassurances that they would be so heavily sedated that "they will not hear or see anything in the operating room". Nearly all of the patients in each group would recommend the same anaesthesia management that they received to other patients and both LA and GA patients enjoyed the possibility of shorter hospital stays.

\section{Discussion}

The aim of the study was to investigate the the safety and feasibility of GA compared with LA+MAC, especially for oneday thyroid surgery involving patient and operator satisfaction with either of the anaesthetic approaches for thyroid surgery. Most studies which reported on one-day surgery of thethyroid gland used a very different observation period postoperatively and discharged patients after between $6^{\text {th }}$ and $24^{\text {th }}$ hours $(14,15)$. They used this approach only in otherwise healthy ASA I and II patients. $50 \%$ of our patient cohort was ASA III; moreover we had 2 patients ASA IV-both with end stage renal failure and haemodialysis 4 times weekly. For this reason, we choose a 23 hour observational period. Due to the low complication rate, we did not use PACU and, after completion of the procedure, we admitted patients irrespectively of the anaesthesia method in GUODS.

The advantages of general anaesthesia are well known. These are; total loss of awareness of the surgical procedure by the patient; immobile operative field for the surgeon, and controlled airways for the anaesthesiologist. The disadvantages of general anaesthesia are possible prolonged postanaesthesia recovery and adverse effects. In our series we did not observe any of them. Patients were fully awake approximately $5 \mathrm{~min}$. after the skin closure. To achieve this, we modified the GA protocol: first-we used Isoflurane, one of the modern inhalational anesthetics, with low partition coefficients and with short context-sensitive half-time; second-we used no muscle relaxation at all, third-to saturate opiate receptors entirely throughout the central nervous system, the total opiate dose was given in increments, but before the skin incision. We achieved a deep level of self-limited anaesthesia with very rapid recovery, without adverse effects, due to the pharmacokinetic profile of Fentanyl citrate-deep postoperative analgesia.

According to one of the most popular myths about thyroid anaesthesia, the advantages of LA with MAC to the patient are faster postanaesthesia recovery, no throat or vocal cord irritation, and potential avoidance of some of the adverse effects of general anaesthesia. Our results refute this. However, the disadvantages of local anaesthesia with MAC are many. For the patient, these are full awareness of being operated on and the sense of pulling and pressure on the surgical wound. Patients who are demented, anxious, agitated, claustrophobic or have language barriers could not tolerate this approach. The surgeon has to contend with occasional motion of the operative field with swallowing, coughing, or patient movement; the anaesthesiologist has to monitor the adequacy of sedation and the airway patency very closely and accurately, with frequent adjustments of the level of sedation for patient comfort, while maintaining proper oxygenation. The quality of voice, is not satisfactory because of sedation, so neuromonitoring of the recurrent laryngeal nerve using a voice contact with an awake patient is also unreliable.

We had no conversions from LA+MAC to general anaesthesia in our study. Lo Gerfo (12) reported a similarly low conversion rate. These and many others have effectively used deep cervical plexus block along with an anterior field block for local anaesthesia (7). We used SCPB with just an anterior field block. This is technically easier and avoids the potential injection of the carotid artery or block of the vagus nerve with a deep cervical plexus block. Intraoperative analgesia was excellent. The earlier appearance of postoperative pain and its high intensity, from our point of view, is due to the pharmacokinetic profile of Lidocaine. Obviously, by using long acting local anesthetics such as bupivacaine, chirocaine, this problem will be solved.

Undoubtedly, early discharge of patients following thyroidectomy is problematic since potentially life-threatening neck hematoma has been documented to occur beyond a short-stay, 6-hour, observation period (16-19). Some authors have suggested that early discharge of patients may result in increased mortality due to this serious complication occurring outside a hospital setting $(16,18)$. We accept a 23-hour observation period in order to assure safe discharge of patients, not only because of the need for observation of any signs of life-threatening airway compromise, but furthermore $>50 \%$ of the patients in our series were ASA III and IV. With an observation period for 23 -hours, an additional $38 \%-50 \%$ of serious complications, otherwise missed with early discharge, would be noticed (21); supporting longer hospital stays for thyroidectomy procedures (16-19).

Many authors (20) reported a very high incidence (>50\%) of postoperative nausea and vomiting. Our results showed that the rate of nausea and vomiting was similar in both anaesthesia groups, which suggests that GA per se is not a promoting factor, and that our prophylaxis protocol is very effective. The incidence of other minor complications such as voice change, asymptomatic hypocalcaemia or transient vocal cord paresis was similar in both groups. So, they could not be attributed to GA alone. Overall, more than $56 \%$ of the patients in both groups had no postoperative complication.

Another of the most popular myths about thyroid anaesthesia is the assumption that thyroid patients have difficult intubations. In our practice, the incidence of difficult but successful intubations was 3, 3\% (95\% Cl: $1.01-6,9)$, which is much lower than the incidence in the total patient population $(\approx 6 \%)$.

Study limitations: We realize that our results are drawn from a single center study, but the responsible endocrine surgeon and anaesthesiologist are highly experienced operators with a special expertise in thyroid and one-day surgery. More observations are needed to prove these results and to validate the protocols.

\section{Conclusion}

The outpatient approach is very well accepted by patients and is feasible and medically safe, if reasonable judgments 
and precautions are used. It requires a high level of surgical expertise, close supervision, open communication, and a motivated, educated patient. In selected patients, LA+MAC for thyroidectomy is a safe and wise approach, but we give priority to GA. The two methods are equally safe and could be offered to one-day thyroid surgery patients, keeping in mind that, in selected patients, LA with MAC is a wise choice, but GA, in experienced hands, and especially in cases of more extensive, complicated surgery, or patient comorbidities, is even more so!

\section{Conflict of Interest}

No conflict of interest was declared by the authors.

\section{References}

1. Spanknebel K, Chabot JA, DiGiorgi M, Cheung K, Lee S, Allendorf J, et al. Thyroidectomy Using Local Anaesthesia: A Report of 1,025 Cases over 16 Years. J Am Coll Surg 2005;201:375-85. [CrossRef]

2. Sahai A, Symes A, Jeddy T. Short-stay thyroid surgery. Br J of Surg 2005;92:58-9. [CrossRef]

3. Ortega J, Cassinello N, Lledy S. 'Same-day' thyroid surgery. Results after 805 thyroidectomies in a fast-track. Cirurgía Esp 2007;82:112-6. [CrossRef]

4. Segerdahl M, Warren-Stomberg M, Rawal N, Brattwall M, Jakobsson J. Clinical practice and routines for day surgery in Sweden: results from a nation-wide survey. Acta Anaesthesiol Scand 2008;52:117-24. [CrossRef]

5. Teoh AY, Tang YC, Leong HT. Feasibility study of day case thyroidectomy. ANZ J Surg 2008;78:864-6. [CrossRef]

6. Mirnezami R, Sahai A, Symes A, Jeddy T. Day-case and shortstay surgery: the future for thyroidectomy? Int J Clin Practice 2007;61;1216-22. [CrossRef]

7. Chin CW, Loh KS, Tan KS. Ambulatory thyroid surgery: an audit of safety and outcomes. Singapore Med J 2007;48:720-4.

8. Materazzi G, Dionigi G, Berti P, Rago R, Frustaci G, Docimo G, et al. One-Day Thyroid Surgery: Retrospective Analysis of Safety and Patient Satisfaction on a Consecutive Series of 1,571 Cas- es over a Three-Year Period. Eur Surg Research 2007;39:182-8. [CrossRef]

9. Chapuis Y, Icard P, Fulla Y, Nonnenmacher L, Bonnichon P, Louve $A$, et al. Parathyroid adenomectomy under local anaesthesia with intra-operative monitoring of UcAMP and/or 1-84 PTH. World J Surg 1992;16:570-5. [CrossRef]

10. Ditkoff BA, Chabot J, Feind C, Lo Gerfo P. Parathyroid surgery using monitored anaesthesia care as an alternative to general anaesthesia. Am J Surg 1996;172:698-700.

11. Chen H, Sokoll LJ, Udelsman R. Outpatient minimally invasive parathyroidectomy: a combination of sestamibi-SPECT localization, cervical block anaesthesia, and intraopertive parathyroid hormone assay. Surgery 1999;126:1016-22. [CrossRef]

12. Lo Gerfo P, Ditkoff BA, Chabot J, Feind C. Thyroid surgery using monitored anaesthesia care: an alternative to general anaesthesia. Thyroid 1994;4:437-9. [CrossRef]

13. Ramsay MAE, Savege TM, Simpson BRJ \& Goodwin R. Controlled sedation with alpaxalone-alphadolone. Br Med J 1974;2:656-9. [CrossRef]

14. Marohn MR, LaCivita KA. Evaluation of total/near total thyroidectomy in a short-stay hospitalization: safe and cost-effective. Surgery 1995;118:943-8. [CrossRef]

15. McHenry CR. "Same-day" thyroid surgery: an analysis of safety, cost savings, and outcome. Am Surg 1997;63:586-90.

16. Foster RS Jr. Morbidity and mortality after thyroidectomy. Surg Gynecol Obst 1978;146:423-9.

17. Burkey SH, van Heerden JA, Thompson GB, Grant CS, Schleck $C D$, Farley DR. Reexploration for symptomatic hematomas after cervical exploration. Surgery 2001;130:914-20. [CrossRef]

18. Lacoste L, Gineste D, Karayan J, Montaz N, Lehuede MS, Girault $M$, et al. Airway complications in thyroid surgery. Ann Oto Rhino Laryngol 1993;102:441-6.

19. Abbas G, Dubner S, Heller KS. Re-operation for bleeding after thyroidectomy and parathyroidectomy. Head Neck 2001;23:5446. [CrossRef]

20. Sonner JM, Hynson JM, Clark O, Katz JA. Nausea and vomiting following thyroid and parathyroid surgery. J Clin Anaesth 1997; 9:398-402. [CrossRef]

21. Rosenbaum MA, Haridas $M$, McHenry CR. Life-threatening neck haematoma complicating thyroid and parathyroid surgery. Am J Surg 2008;195:339-43. [CrossRef] 